\title{
Kolm tegelast poola naljades
}

\begin{abstract}
Dorota Brzozowska
Teesid: Käesoleva artikli eesmärk on kirjeldada poola anekdoote kolmest tegelasest, ning anda ülevaade nende ajaloost ja muutumisest. Keskendutakse kolmese ülesehitusega naljadele, mille sisu on muutunud etnilisest ametitega seonduvaks. Artikkel püüab vastata kesksele küsimusele, kui universaalsed või kultuurispetsiifilised on sellised naljad. Folkloorne ja globaalselt levinud ettekujutus numbri 3 tähendusest pakub samuti huvitavaid sissevaateid kolme tegelasega anekdootide olemusse. Kirjeldatakse stereotüüpseid juhte, kus erinevate rahvuste esindajad käituvad oodataval moel, ning analüüsitakse kõnealuste anekdootide erinevate aspektide - etniliste, poliitiliste, seksuaalsete, loogiliste ja muude - omavahelist põimumist.

Poola lähimate ja ajalooliselt seotuimate naabrite, venelaste ja sakslaste, rollist Poola kultuuris annab aimu ka nende tegelaste sage esinemine kolme rahva naljades. Selles artiklis vaadeldaksegi nalju nende kahe etnose ja teiste populaarsete tegelaste (tšehhid, ameeriklased, programmeerijad jt) kohta ning nimetatud tegelastega seotud arvamusi ja stereotüüpe poola kultuuriruumis. Selle abil saame vastata küsimusele, kas etniliste stereotüüpide olemasolu tänapäeva anekdootides on veel tuntav või on need vahetumas millegi populaarsema vastu.
\end{abstract}

Märksõnad: etnilised demotivaatorid, etnilised stereotüübid, kolme tegelasega naljad, nalja objekt, poola huumor

Artikli eesmärk on analüüsida poola nalju kolmest tegelasest. Uurimismaterjal koosneb neljasajast anekdoodist, mis on võetud anekdoodikogumikest, teistest trükitud allikatest ja internetist. Diakroonilise analüüsi abil osutatakse kokkuvõtvalt anekdooditraditsiooni erinevustele varasematel aegadel ja tänapäeval. Eriti nähtavad on metamorfoosid enne ja pärast 1990. aastaid: Poola poliitiline olukord muutus kiirelt pärast 1989. aastat ning sellega paralleelselt muutusid ka anekdootide teemad, vorm ja levikuviis (vt ka Brzozowska \& Chłopicki 2012).

Peamine erinevus 20. sajandil tuntud kolme tegelasega anekdootide ja praeguste vahel on see, et teemade hulka on lisandunud hulgaliselt selliseid, mida varem peeti tabuks. See tähendab, et anekdoodid on nüüd tihti seksuaalse 
sisuga, sagenenud on naljad vaimulikest ning hea ja halva maitse piiril balansseerivad katastroofianekdoodid või must huumor. Seegi on seotud tsensuuri kadumise ja sõnavabaduse tekkimisega totalitaarse režiimi lagunedes. Suhteliselt hiljuti võidetud vabadus kritiseerida ühiskonnanähtusi avalikus meedias - ajalehetedes, raadios, televisioonis, internetis - on üks põhjustest, miks poliitilised anekdoodid, mida oli enne iseseisvumist ülikülluslikult, hakkasid 1990. aastatel igapäevasuhtlusest kaduma. Kadusid naljatsüklid, mis naeruvääristasid totalitaarset režiimi ja poliitikuid. Kaasaegsed poliitikud, presidendid ja peaministrid pole enam nii sagedased huumoriobjektid, ja poliitilise huumori kategooria on muutunud üldiselt hajusamaks. Vahetevahel pilatakse üksikutes naljades poliitikute päevakajalisi otsuseid, ja need naljad paistavad silma oma suhteliselt lühikese elueaga. Ringleb ka kuulsuste kohta käivaid anekdoote, kuid ka need ei moodusta kindlat kategooriat ja neid võib käsitleda osana moevoolust (postsotsialistliku huumori kohta Ida-Euroopas vt lähemalt Brzozowska 2009; Krikmann \& Laineste 2009).

Totalitaarse režiimi langus, poliitiline vabadus ja raudse eesriide langemine ning peatselt järgnenud ühinemine Euroopa Liiduga on põhjustanud poola kultuuris mitmeid muutusi, eelkõige varem keelatud ja salaja imetletud lääneliku kultuuri trendide kiiret omaksvõtmist. Uued naljatsüklid, mis jõudsid Poolasse Ameerika Ühendriikidest, on saanud naljatraditsiooni lahutamatuks osaks (Brzozowska 2008). Samuti on tunda tugevaid inglise keele mõjutusi. Ka naljatekstides endis on muutusi: anekdoodid räägivad sageli mõnest globaalse tähendusega probleemist, teemad on rahvusvahelise iseloomuga, ning naljade edastamisel (rääkimisel ja kirjutamisel) kasutatakse võõrkeelseid sõnu. Paljud tekstid, mis poola teismeliste hulgas ringlevad, ongi ingliskeelsed - noor generatsioon õpib inglise keelt esimese võõrkeelena ja seda praktiseeritakse iga päev, näiteks internetisuhtluses.

Erinevus kirja- ja kõnekeele vahel muutub aina väiksemaks terves maailmas, tänapäeva Poolas samuti. Keele demokratiseerumine ja samaaegne vaesumine on nähtav peaaegu igas kommunikatsioonikanalis. Kasutatakse argikeelseid sõnu, vulgarisme, agressiivseid väljendeid; peent ja viimistletud stiili ning keelemängu kohtab aina harvem. See kehtib ka huumori kohta, kus esiplaanile trügib situatsioonikoomika ja tordiga-näkku-naljad.

Huumoril on igapäevaelus varasema ajaga võrreldes uus koht. See ümbritseb meid pidevalt kõikides meediakanalites: ajakirjades, kollases ajakirjanduses, reklaamides jne. Televisioon ja internet pakuvad loendamatuid võimalusi huumori loomiseks, edastamiseks ja tarbimiseks. Ka muutus, mida ühiskond on läbimas kirjalikkuse asendumisel pildilisusega, mõjutab huumorižanre. Anekdootide asemel levivad nüüd naljakad pildid, mida vahel iseloomustab 
rida teksti, nt peal- või allkiri. Naljakad lühifilmid ja nn koduvideod, aga ka joonistused ja fotod domineerivad huumorimaastikul. Kõik see annab tunda huumori külluslikust, kuid muutunud kohalolekust meie igapäevases meediatarbimises.

Üks käesoleva artikli eesmärke on analüüsida detailsemalt muutusi konkreetses anekdoodikategoorias, kolme tegelasega anekdootides, mis on üks populaarsemaid ja tähenduslikemaid naljakategooriaid Poolas. Enne Teist maailmasõda oli Poola väga multikultuurne riik: seal elas palju rahvusi, kes kuulusid erinevatesse kultuuriruumidesse ja rääkisid erinevaid keeli. Sõjajärgsetel aastatel ja sotsialismiajastu alguses juurutati ideoloogiat, mille keskmeks oli üks riik, üks rahvus ja üks keel. Kuid pärast 1989. aastat hakati rõhutama hoopis kohaidentiteedi ning dialektide ja regionaalse kogukonna tähtsust. See muutuste ahel peegeldus ka etnilistes naljades, mille aluseks on rahvusstereotüübid.

Üks populaarsematest etniliste naljade tsüklist, nn kolme rahva anekdoodid, põhineb kolmeastmelisel ülesehitusel, mis on meile tuntud paljude rahvaste folkloorist. Kui näiteks Briti traditsioonis on nendes naljades tegelasteks inglane, iirlane ja šotlane (Davies 1990; 2005), siis Poolas on vastavaks kolmikuks poolakas, venelane ja sakslane. ${ }^{1}$

Varaseimad naljad, mida võib käsitleda sellesse kategooriasse kuuluvana, seostuvad vana legendiga kolmest vennast, kelle nimed olid Lech, Čech (või Czech) ja Rus. Pärimuses on nende teeneks kolme slaavi rahvuse loomine: Lech pani alguses Lechiale (praegune Poola), Čech asutas Tšehhimaa ja Rus Ruteenia (praegune Venemaa, Valgevene ja Ukraina). Sellel legendil on erinevaid versioone, kuid üks poola tekstidest kirjeldab, kuidas vennad läksid koos jahile, järgnesid erinevatele jahiloomadele ning sattusid üksteisest lahku. Rus kõndis ida poole, Čech ajas jälgi lääne suunas ja jõudis Boheemia mägisele alale, samal ajal kui Lech rändas saaki otsides põhja poole. Oma lendulastud noolt otsima minnes kohtus viimane vend valge kotkaga, kes kaitses oma pesa sissetungijate eest. Valge kotkas punase loojangu taustal tundus Lechile hea endena ja ta lõi sinnasamasse asunduse, mille nimeks sai Gniezno (poola keeles tähendab gniazdo pesa). Kotkas sai sestpeale tema vapisümboliks. ${ }^{2}$ Varaseim poola ülestähendus kolmest vennast on aastast 1295 ning see pärineb Gnieznos või Poznańis kirjutatud raamatust Suur-Poola kroonika (Kronika wielkopolska).

Legend osutab uskumusele, et poolakad, tšehhid ja ruteenlased (venelased) põlvnevad ühest sugupuust ja faktile, et see teadmine oli levinud juba 13. sajandil, kui mitte varem. On alust arvata, et juba siis mõistsid nende alade elanikud, et nad on etniliselt ja keeleliselt sarnased. Legendi kolme venna nimed viitavad etnonüümide päritolule. 
Slaavlased on hästi esindatud ka poola vanemas rahvapärimuses, eriti selles, mis on pärit piirialadelt. Kuid 20. sajandil sai kõige olulisemaks etniliseks "teiseks" juut. Teise maailmasõja päevil see muutus ning juutide koha võtsid üle liitlased ja sakslased, veelgi hiljem said pilkeobjektiks venelased. Kaks viimatinimetatud rahvust, kes on ühtlasi Poola olulisemateks naabriteks, esinesid poolaka partneritena kolme rahvuse naljas, kus kõrvuti tegutsesid klassikalises triaadis poolakas, sakslane ja venelane. Külma sõja perioodil räägiti ka selliseid anekdoote, kus venelase partneriks oli ameeriklane, ja kus need kaks tegelast moodustasid kontrastse paari vastavalt halvast ja heast, negatiivsest ja positiivsest. Uusimates naljades on aga ameeriklased haaranud domineerivama positsiooni, täiendades juurdunud poolakas-sakslane-venelane kolmikut neljanda osapoolena või vahetades ühe neist välja.

Tavaliselt on kolme rahva naljades keskmine (ehk siis teisel kohal) olnud sakslane. See on positsioon, millel puudub konkreetne karakter ja mida anekdoodis pikemalt ei kirjeldata, nö täitepositsioon. Keskmistele tegelastele ei juhtu kunagi jäädavat kahju ja anekdooditeravik pole suunatud kunagi nende pihta. Et poolakas on tavaliselt see, kes saavutab (vahel kahtlase väärtusega) võidu teiste tegelaste üle ja venelane jääb enamasti kaotaja positsioonile, positsioneerub sakslane keskmisele kohale, kus teda aeg-ajalt asendavad samaväärsed vähetähenduslikud etnilised teised. Tüüpilise stsenaariumi näiteks kolme rahva naljas toome siinkohal järgmise teksti:

Toimus võistlus naelte peaga seinalöömises. Kirja oli end pannud kolm osalejat: poolakas, sakslane ja venelane. Esimesena lööb sakslane, lööb üks... kaks... kolm... ja ongi nael seinas. Teisena lööb poolakas: Üks... kaks... nael sees. Viimane on venelane: Üks... valmis! Siis teatatakse otsus: sakslane jäi teiseks, poolakas esimeseks ja venelane on viimane, sest tema lõi naela seina tagurpidi, tömp ots eespool.

(www.dowcipy.ugu.pl/dowcipypolak3.html - 24. oktoober 2012)

Sõja järel hakkasid mõned etnilised grupid naljadest kaduma ja nende asemele ilmusid uued tegelased. Näiteks anekdoodid, mis naersid varem juutide kitsiduse üle, võtsid nüüd sihtmärgiks šotlased, mõnedes teistes aga kadus etnilisus sootuks. Viimastel aastakümnetel on huvi juutide ja nende kultuuri suhtes jälle suurenenud, mis on mõnel määral taaselustanud ka juudinaljade traditsiooni. On ka etnilisi tegelasi, keda varem üldse ei esinenud ja kes on alles nüüd pilkeobjektiks saanud: näiteks pärast Poola liitumist Euroopa Liiduga lisandus anekdoote, mis pilavad Euroliitu kuuluvaid rahvusi, aga ka liitu ennast ja selle ametnikke üldisemalt. Huvi Aasia kultuuri vastu, aga ka sealsete riikide kiire majanduskasv ja läbimurre Euroopa turule, on põhjustanud nende naljade sagenemist, mis räägivad hiinlastest, jaapanlastest jm. 
Internetikeskkond on loonud eeldused anekdootide kiireks rahvusvaheliseks levikuks. Tänu sellele on naljad, mis algselt käibisid väikeste kohalike etniliste rühmade kohta, võetud kasutusse globaalselt; nende levikuala on nüüd märgatavalt suurem. Aina lihtsustuv ligipääs internetile on suurendanud selle meedia rolli eelkõige just noorte igapäevaelus. Seal liigub ka huumor, ning see võtab internetikeskkonnas uusi vorme. Väga populaarseks on osutunud visuaalse materjali kasutamine naljakate märksõnade, ütluste jm illustreerimiseks. Levib amatöörvideote ja demotivaatorite osakaal huumorisaitidel. Et muutunud on nii huumori vorm kui sisu, pakub praegune situatsioon huvitavaid võrdlusmomente varasema ajaga, seda ka traditsioonilise kolme tegelasega nalja osas.

Üks levinumaid huumorižanreid internetis on, nagu juba mainitud, demotivaatorid (viimastest saab lugeda pikemalt Tomasz Piekoti artiklist Mäetaguste käesolevas numbris, vt ka Baran 2012). Seda on defineeritud kui demotiveerivat piltsõnumit, mis koosneb pildist (joonistusest; sagedamini fotost) ja kommentaarist või pealkirjast, mis visuaali täiendab. Demotivaatorid on olemuselt küünilised ja iroonilised, millele viitab ka nende arengulugu motivatsioonipostritest demotivaatoriteks. Kui motivatsioonipostrite eesmärk oli innustada töötajaid (Ameerika Ühendriikide) kontorites, et nad pingutaksid ja saavutaksid rohkem, siis demotivaatorid keeravad selle tähenduse pea peale. Need iroonilised naljapildid levivad kiirelt ja kommenteerivad mõnuga päevasündmusi või muid, igihaljaid teemasid, nagu sugude- või rahvustevahelised suhted.

2012. aasta olulisem sündmus Poolas oli jalgpalli eurokarika finaalvõistluse korraldamine Poolas ja Ukrainas. EURO 2012 ei pakkunud huvi ainult jalgpallifännidele vaid mõjutas kogu Poola riiki ja rahvust tervikuna, kui otsustada tuliste väitluste põhjal, mida peeti meedias selle korraldamise üle. Spordisündmused on üldiselt väga sobivad ja efektiivsed nähtused selleks, et taasäratada ja tugevdada rahvusidentiteeti; nii oli ka selle sündmuse taustal hästi näha, kuidas toimivad etnilised stereotüübid ning mis faktorid mõjutavad positiivselt või negatiivselt identiteediloomet.

Esimene (visuaalne) kommentaar EURO 2012-le leidus internetis kohe pärast otsust, millised võistkonnad omavahel võistlevad. Et loosi tahtel sattusid ühte alagruppi Poola koos Tšehhi ja Venemaaga, ning neljandaks osutus selles alagrupis Kreeka, on ootuspärane, et jalgpallifännidel tekkis sellise jaotusega palju seoseid ja stereotüüpe. Muuhulgas aktiveeris see legendi kolmest slaavi vennast, mis sai kohemaid uue elu ja uusi variatsioone.

Teises näites nimetatakse samuti kolme traditsioonilist tegelast - Lech, Czech, Rus - ning neljanda osapoole puhul tuuakse välja riigi nime (Kreeka, ingl. k. Greece) sarnasus poolakeelse sõnaga 'kryzys', so 'kriis'. 


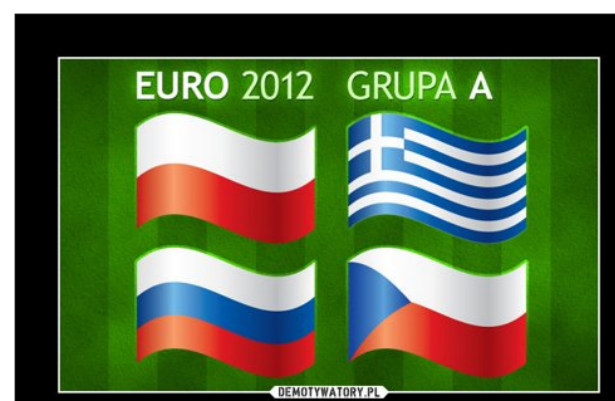

Niby w naszej grupie rodzinna atmosfera

bo Lech, Rus I Czech, ale nie ma co udawat Greka bo tylko 2 przejdzie dalej
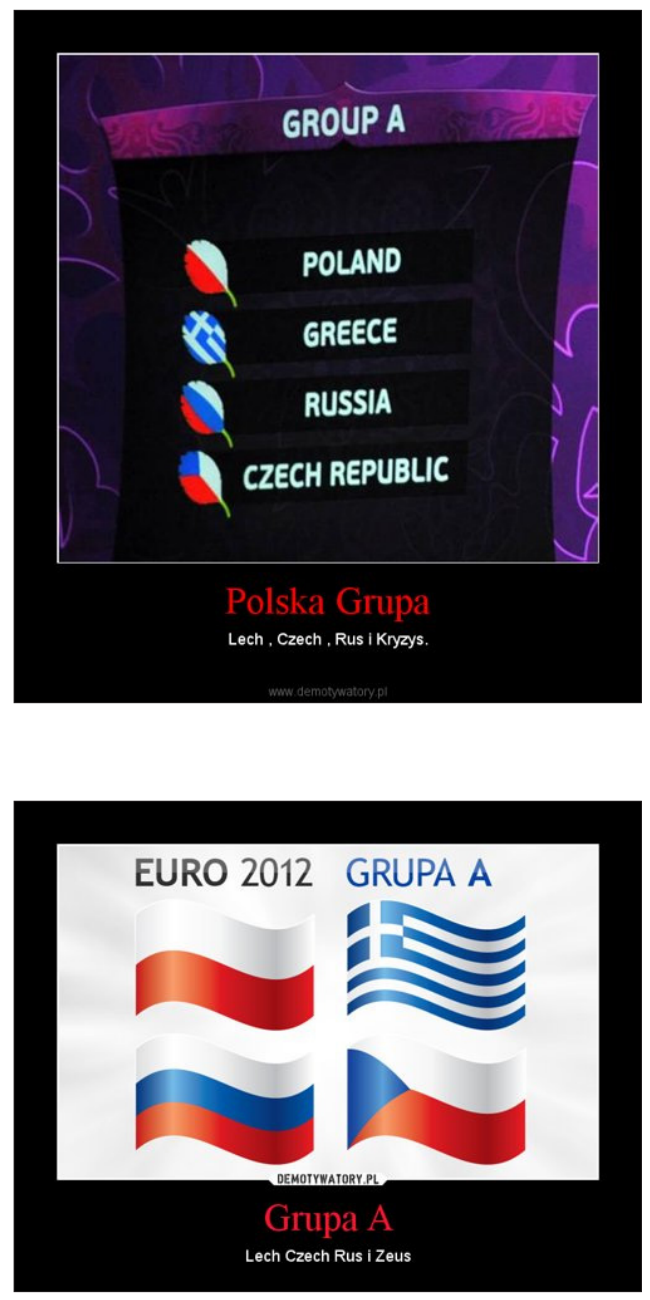

Joonis 1. Tundub, et selles alagrupis on vennalik õhkkond, kuid mis me siin ikka kreeklast mängime (poolakeelne väljend, mis tähendab 'lolli mängima'): ainult kaks neist kvalifitseeruvad! (http: / / demotywatory.pl/3809772 /Niby-w-naszej-grupierodzinnaatmosfera -24. oktoober 2012).

Joonis 2. Poola grupp. Lech, Czech, Rus ja Kriis (http: / / demotywatory.pl/3587513/ Polska-Grupa-24. oktoober 2012).

Joonis 3. Grupp A: Lech, Czech, Rus ja Zeus (http: / / demotywatory. pl/3826521/Grupa-A - 24. oktoober 2012). 
Ka selles demotivaatoris (joonis 3) on samad neli elementi (neli riiki), kuid siin viidatakse "üleliigsele neljandale" viimase kultuuritausta kaudu. Traditsioonilist etnilist kolmikut, kes seisavad vastamisi neljanda, nö liigse tegelasega, kasutatakse ka naljades. See kinnitab taas, et kolme reegel on traditsioonis sügavalt juurdunud ja isegi juhul, kui see pole pidevalt esiplaanil, võivad teatud tingimused (antud näites jalgpallivõistluse alaliidu loositulemused) neid implitsiitseid seoseid kiirelt esile kutsuda.

Selles näites on viited ajaloolistele sündmustele, mille käigus õnnestus Poolal edukalt rünnata Venemaad ja saavutada (olgugi lühiajaline) võit. Nähtaval kohal on ka nende kahe riigi vaheliste suhete teravus ja poliitilisus. Pilt on üles ehitatud kolmeosaliselt (mis pole väga tavaline lahendus; aja ja ruumi kokkuhoiu mõttes on demotivaatorid enamasti lihtsad ja ühe pilguga haaratavad), kasutades visuaalis ära reeglit, millele on üles ehitatud ka kolme tegelasega anekdoodid või millele viitab ütlus "kolm on kohtu seadus", et rõhutada ajaloolisi paralleele tänapäevaga ning väljendada lootusrikkust eelseisva spordivõistluse suhtes.

Anekdoodid kolmest etnilisest tegelasest on küll väga populaarsed, kuid pole ainukesed sellise ülesehitusega naljad. Varasemast poola anekdooditraditsioonist pärinevad naljad,

Joonis 4. 1612 - poolakad vallutavad Kremli; 1812 - poolakad vallutavad taas Kremlit koos Napoleoni armeega; 2012 - 12. juunil toimub Poola-Venemaa jalgpallimatš. " $M a$ ei usu numeroloogiasse, aga mul poleks midagi selle vastu, kui traditsioon jätkub" (http: / / demotywatory.pl/3823901 / Nie-mam-przesadownumerologicznych - 25. oktoober 2012).

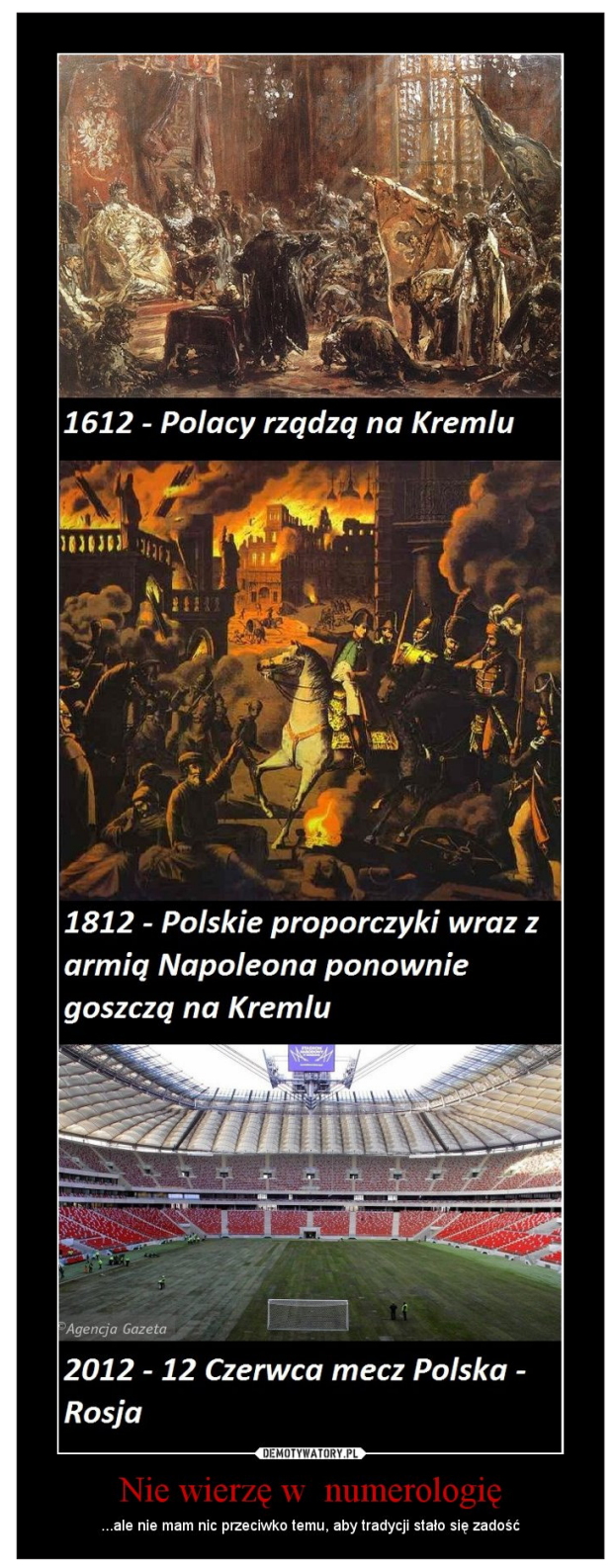


kus erinevate religoonide esindajad vaidlevad või arutlevad millegi üle samuti kolmekaupa. Tavaliselt on sellistes naljades tegelasteks preester, pastor ja rabi, kes üritavad tõestada oma usu üleolekut teiste omast. Nad esitavad oma seisukohti usu, kommete ja väärtuste kohta:

Preester, pastor ja rabi sõidavad rongiga. Preester suurest taktitundest ja rabi suurest tarkusest ei taha rääkida tundlikel teemadel, aga pastor tahab kangesti provotseerida ja alustab vaidlust. Seepeale ütleb rabi: "Härra pastor! Kui messiast veel pole tulnud, siis on juutidel õigus; kui messias on juba tulnud, siis on katoliiklastel õigus, aga sinul pole mingil juhul õigus.”

(Księga dowcipu (avaldatud 20. sajandil ilma märkuseta väljaandmisaasta kohta): 385)

Mõned naljadest on ajakohased tänaseni, eriti kui vaieldakse mõnel praegugi peavalu valmistaval teemal:

Preester, pastor ja rabi vaidlevad selle üle, mis hetkel saab alguse inimese elu.

Preester: "Inimelu algab siis, kui munarakk ühineb seemnerakuga."

Pastor: "Inimelu algab hetkel, kui viljastunud munarakk kinnitub emakaseinale."

Ja rabi ütleb selle peale: "Härrased! Inimelu algab hoopis siis, kui sinu naine sureb, sinu koer sureb, ja sinu lapsed kolivad välja!”

(rozrywka.57.pl/kaw-4-o,religii/ - 28. september 2012)

Kolme tegelasega nalju leidub ka vaid ühe etnilise grupi kohta, näiteks uusrikate (uusvenelaste) anekdoodid kasutavad mõnikord kolmest struktuuri:

Kolm rikast ärimeest räägivad ärijuttu ja joovad viina. Esimene hoopleb: "Mul on nii palju pappi, et ma võin osta oma tütre sünnipäevaks ära suurima telefonifirma."

Teine ütleb seepeale: "Ma olen ka hullult rikas ja ma võin üldse kõik telefonifirmad üles osta.”

Siis vaatavad nad oma kolmanda sõbra poole. See ei kosta tükk aega midagi, ja siis ütleb: "Mis te mind vahite? Ei, mis te arvate, et ma mü̈n need tõesti teile või?"

(http://dowcipy.pisze.se/10.02.2012)

Sellised anekdoodid võivad osutuda ajutiselt populaarseks, kuid enamasti ei teki neist naljatsüklit, kus sama reeglit kasutatakse aina uuesti ja uuesti.

Sellegipoolest on mõni alaliik kolme tegelasega nalju osutunud ka nii populaarseks, et samade tegelasega temaatiliselt ja struktuuri poolest seotud nalju koguneb aja jooksul terve hulk. Tänapäeval annavad anekdooditsükli 
mõõdu välja näiteks naljad, mis räägivad matemaatikust, füüsikust ja IT-mehest (programmeerijast).

Programmeerija, füüsik ja matemaatik peavad võrdse hulga okastraadiga ära piirama võimalikult suure pindala. Programmeerija ümbritseb ruudukujulise ala. Füüsik, veidi targemana, piirab ära ringikujulise ala ja väidab, et paremini ei ole võimalik seda ülesannet lahendada. Matemaatik teeb okastraadist väikese aiakese, ronib sinna sisse ja ütleb: "Ma olen väljas.” (http://naukowcy.dowcipy.pl - 25. oktoober 2012)

Kui need kolm tegelast omavahel anekdoodis suhtlevad, siis enamasti on rollid jagunenud alati ühtemoodi: matemaatik on tark tegelane, kes on küll pisut elukauge, kuid muidu üsna edukas. Mõnel määral kehastab ta hajameelset teadlast, kes elab oma maailmas. Füüsik on maalähedane, praktiline ja realistlik. Programmeerija aga on alati nalja objekt, see, kes jääb naljas naerualuseks. Vahel võidakse tegelasi ka teiste (sarnaste) erialade esindajate vastu vahetada.

Progammeerija, keemik ja insener sõidavad autoga. Äkki hakkab mootor vilistama, turtsuma, ja siis jääb hoopis seisma.

Insener ütleb: "Mootoril on midagi viga."

Keemik ütleb. "Bensiin oli vist vilets."

Programmeerija soovitab: "Lähme kõik korraks välja ja tuleme sisse tagasi, restart enamasti aitab.”

(http://naukowcy.dowcipy.pl - 25. oktoober 2012)

Kolm tü̈̈pi vaatavad üht maja. Äkki läheb kaks inimest majja. Poole tunni pärast tuleb kolm inimest majast välja.

Bioloog ütleb: "Nad paljunesid."

Fü̈̈sik ütleb: "Ei, see on mõõtmisviga."

Matemaatik ütleb: "Kui üks inimene veel sisse läheks, oleks maja tühi." (http://naukowcy.dowcipy.pl - 25. oktoober 2012)

Enamasti räägivad sellised naljad reaalteadlastest, kuid vahel harva on kontrastiks toodud ka mõni humanitaarala esindaja.

Matemaatik, fü̈̈sik ja poola filoloog arutlevad, kumb on parem, naine või armuke.

Matemaatik ütleb: "Naine on parem, sest siis on õhtusöök alati valmis ja maja korras.”

Fü̈̈sik ütleb: "Armuke on parem, sest ta lõhnab alati hästi ja tahab seksida."

Poola filoloog vastab neile: "Mõlemad on head. Minu naine arvab, et ma olen armukese juures, ja armuke arvab, et ma olen kodus, aga tegelikult saan rahulikult raamatukogus tööd teha."3 


\section{Kokkuvõte}

Kolme tegelasega naljad on aastate jooksul läbi teinud üsna põhjaliku muutuse. Selle põhjuseks on muuhulgas muutunud poliitiline ja majanduslik olukord. Päris alguses tähendas klassikaline triaad legendidest tuttavat kolme slaavi hõimlast (vt ka Laineste \& Brzozowska 2011). 20. sajandil asendus see sel ajal oluliste etniliste "teiste" kolmikuga: poolaka, venelase ja sakslasega. Külma sõja perioodil lisandus anekdooditüüpi ameeriklane, vahel neljanda tegelasena, vahel sakslase asendusena. Pärast iseseisvumist ja sellega kaasnenud digitaalset revolutsiooni sai anekdooditraditsioon juurde hulgaliselt uusi etnilisi tegelasi: Euroopa Liidu liikmesriikide esindajaid, asiaate (jaapanlasi, hiinlasi), jt. Sakslane on anekdootidest praeguseks peaaegu kadunud, kuid venelased on jäänud: nende uus tüüpanekdoot on seotud püstirikka ja ärahellitatud uusvenelase karakteriga.

Mõned päevasündmused võivad vanu ja näiliselt unustatud stereotüüpe taas tugevdada. See juhtus näiteks EURO 2012 jalgpallivõistluste käigus, kui ühte alagruppi sattusid üksteise vastu mängima kolm slaavi hõimlast, poolakad, tšehhid ja venelased, ja neljandaks Kreeka. Kui Poola võistkond mängis Venemaa vastu, tõusid ühiskonnas pinnale vana antipaatia ja minevikusuhete poliitilisus. Näiteks korraldasid vene jalgpallifännid just matši toimumise päeval, 12. juunil, Varssavi tänavatel suurejoonelise vene festivali, et tähistada Venemaa päeva, mis on suhteliselt vähetuntud, kuid rahvusliku sisuga tähtpäev. Korraldajad lubasid mitte kasutada poliitilisi hüüdlauseid, kuid pidustustest osavõtjad tegid seda siiski, mistõttu tänavatel ja Varssavi Rahvusstaadioni läheduses puhkesid rahutused. Politsei arreteeris üle 180 inimese. Samal ajal olid suhted teiste alagrupikaaslastega, näiteks tšehhidega, väga positiivsed ${ }^{4}$. Isegi pärast kaotust Tšehhile, mille tulemusel Poola langes konkurentsist välja, õnnitlesid poolakad tšehhi võistkonda võidu puhul ja lubasid eelseisvatel lõppmängudel just neid toetada. Seda toetas ka taasäratatud kujund slaavi vendlusest, mis Venemaa puhul otsustati ilmselt tähelepanuta jätta ja keskenduda negatiivsele ühisminevikule, mitte selle positiivsetele lõikudele.

Rahvussetereotüübid pole poola naljades enam nii nähtaval kohal kui varem. Kolme tegelasega naljad on leidnud uued sihtmärgid, mis on etniliselt neutraalsed - näiteks sellised, mis pilavad erinevaid ameteid. Rahvused, keda veel naljades kohata võib, on muutunud: esineb suurem valik etnilisi gruppe, kuid ükski neist pole nii populaarne, et tekiks selleteemaline naljatsükkel. Samas on hulgaliselt anekdoote, mis kasutavad kolme rahva naljadega sarnast ülesehitust, näiteks need, mille tegelasteks on progammeerija, matemaatik ja füüsik. Selles tsüklis pole lihtne osutada sagedasimale tegelasele, sest need kipuvad vahelduma vastavalt naljarääkija vajadustele või rääkimise kontekstile. 
On huvitav märkida, et nii klassikaline kolme etnilise tegelasega anekdoot kui ka hilisemad mitte-etnilised triaadid on olemuselt maskuliinsed ja meestekesksed. Naljad poolakast, sakslasest ja venelasest on ringluses juba ammu, kuid ikka on tegelasteks üksnes mehed ja mitte kunagi naised. Võibolla saab paralleelina siin vastunäiteks tuua tsükli blondiinist, brünetist ja punapeast, mis mõni aeg tagasi oli veel üsna populaarne, aga see meenutab pigem 1990. aastate lõpu ülipopulaarset blondiininaljade lainet ning mõjub selle laiendusena. Kuid klassikalisse triaadi kuuluvad siiski vaid mehed, ning ka näiteks ametitega seotud naljad - näiteks need, milles kolme teadusvaldkonna esindajat mõõtu võtavad - räägivad ainult meestest. Tähelepanuväärne on ka asjaolu, et kolmest struktuuri tuleb tänapäeval üldiselt harvem ette, ning see võib olla seotud anekdoodižanri üleüldise lühenemise ja kompaktsemaks muutumisega.

\section{Tõlkinud Liisi Laineste}

\section{Kommentaarid}

1 Kolme karakteriga ülesehitust kasutatakse ka paljudes teistes žanrites ning see pole tuttav mitte ainult folklooris, vaid ka kirjanduses. Näiteks Anthony Horowitzi romaanis The killing joke (2004) lahendas müsteeriumi kolme etnilise tegelase ilmumine. Vt ka Christie Daviese teooriaid etnilistest naljadest (Davies 1990; 2005).

2 Valge kotkas on Poola sümboliks jäänud tänase päevani, ja selle värv koos päikeseloojangupunasega on Poola lipu värvideks.

3 See nali on levinud ka teiste tegelastega, näiteks arsti, psühhiaatri ja teadlasega (http:// www.dowcipowo.pl/grupa/geekowe/najlepsze-z-najnowszych - 25. oktoober 2012).

${ }^{4}$ Nii väitis näiteks Ziemowit Szczerek artiklis "Czesi nie mogą się nadziwić Polską. Historyczna zmiana stereotypu?" [Tšehhid ei saa poolakatest üle. Stereotüüpide muutumine ajas] (http://fakty.interia.pl/tylko_u_nas/news/czesi-nie-moga-sie-nadziwicpolska-historyczna-zmiana,1810637 - 25. oktoober 2012).

\section{Kirjandus}

Baran, Anneli 2012. Visual humour on the Internet. Laineste, Liisi \& Brzozowska, Dorota \& Chłopicki, Władisław (toim). Estonia and Poland. Creativity and tradition in cultural communication 1. Tartu: ELM Scholarly Press, lk 171-186.

Brzozowska, Dorota 2008. Polski dowcip etniczny. Stereotyp a tożsamość [Poola etnilised anekdoodid. Stereotüübid ja identiteet]. Opole: Wydawnictwo Uniwersytetu Opolskiego.

Brzozowska, Dorota 2009. Polish jokelore in the period of transition. Krikmann, Arvo \& Laineste, Liisi 2009 (toim). Permitted laughter: Socialist, post-socialist and neversocialist humour. Tartu: ELM Scholarly Press, lk 127-169. 
Brzozowska, Dorota \& Władysław Chłopicki 2012 (toim). Polish humour. Humour and Culture 2, Kraków: Tertium.

Davies, Christie 1990. Ethnic humor around the world. A comparative analysis. Indiana: Indiana University Press.

Davies, Christie 2005. Jokes and groups. London: Institute for Cultural Research.

Krikmann, Arvo \& Liisi Laineste 2009 (toim). Permitted laughter: Socialist, post-socialist and never-socialist humour. Tartu: ELM Scholarly Press.

Laineste, Liisi \& Dorota Brzozowska 2011. Eastern European three-nation jokes: A Beta Database. Witalisz, Alicja (toim). Across Borders. Zeszyty Naukowo-Dydaktyczne PWSZ w Krośnie, number 55, Papers on Language, Culture and Literature 3. Krosno: PWN, lk 115-126.

\section{Summary}

\section{Three characters in Polish jokes}

\section{Dorota Brzozowska}

Keywords: three characters in jokes, Polish humour, targets, ethnic stereotypes, demotivators

The aim of this paper is to show how tripartite jokes have developed from ethnic jokes into jokes about professions. The attempt to answer the question about the universal and culture-specific character of those jokes is crucial. The introduction presents the relationships of the current topic with the number three as a folkloric universal. Stereotypical situations prompting the representatives of different nations to behave in a manner characteristic of them are then described, followed by the analysis of the entwining of ethnic, political, sexual, "logical" and other dimensions of humour in tripartite jokes.

The historical contexts and the role that the closest and most relevant neighbours, i.e., the Russians and the Germans, play in Polish culture is presented and compared with the stereotypes and attitudes of other national characters present in jokes (e.g. the Czechs, the Americans). With this, we aim to answer the question if and when ethnic stereotypes are still present in contemporary jokes. 